\title{
Clinical implication of next-generation sequencing for sudden arrhythmia death syndrome
}

\author{
Ling-Ping Lai \\ Cardiovascular Center and Division of Cardiology, Department of Internal Medicine, National Taiwan University Hospital and National Taiwan \\ University College of Medicine, Taipei \\ Correspondence to: Ling-Ping Lai, PhD. Cardiovascular Center and Division of Cardiology, Department of Internal Medicine, National Taiwan \\ University Hospital and National Taiwan University College of Medicine, No. 7, Chung Shan S. Rd., Zhongzheng Dist., Taipei. \\ Email: wtpwtp00@gmail.com.
}

Submitted Jul 30, 2020. Accepted for publication Aug 21, 2020.

doi: 10.21037/apm-20-1509

View this article at: http://dx.doi.org/10.21037/apm-20-1509

Unexpected sudden cardiac death in the young (SCDY) is tragic occurrence and causes terrible grief for the parents, families, school members, and friends of the stricken individuals. In study of a Caucasian population, it was found that $75 \%$ of SCDY cases were not caused by coronary artery disease, which is main cause of sudden cardiac death in adults. Most of these incidents, rather, are caused by inheritable sudden arrhythmic death syndrome (SADS) or genetic cardiomyopathy (GCM), and the prevalence of these diseases ranges from $1 / 1,000$ to $1 / 10,000$.

SADS includes long QT syndrome (LQTS), short QT syndrome, Brugada syndrome (BrS), catecholamine polymorphic ventricular tachycardia, and many kinds of cardiomyopathies. LQTS, for example, is an inborn and inheritable heart disease of a structurally normal heart but entails an increasing risk of life-threatening arrhythmia, such as torsade de pointes (TDP, a form of irregular heartbeat that originates from the ventricles). The condition is so named because of the appearance of a prolonged QT interval on the electrocardiogram. The prevalence of long QT syndrome is close to 1:2000 with the mean age of onset around $10 \pm 20$ years old. The patients with LQTS can present with palpitations, syncope, and sudden death due to ventricular tachycardia/fibrillation (1). In 1957, Jervell and Lange-Nielsen described the first cases of autosomal-recessive LQTS with concomitant bilateral sensorineural deafness, providing the first description of an inherited arrhythmia syndrome associated with sudden cardiac death in structurally normal hearts (2). In 1963 and 1964, Drs. Romano and Ward described the autosomal- dominant version of LQTS with an isolated cardiac phenotype $(3,4)$. No LQTS-causal gene was discovered until 1995 when Mark Keating's research team used linkage analysis with single-strand conformation polymorphism and DNA sequence analyses to identify the KCNH2-encoded Kv11.1 potassium channel and the SCN5A-encoded Nav1.5 sodium channel in families with LQTS $(5,6)$. Two and a half decades later, 14 more minor LQTS-susceptibility genes have been discovered. All 17 genes account for nearly $70-80 \%$ of disorders (7) which indicates that LQTS is typically inherited as an autosomal-dominant trait, is rarely inherited recessively, is and characterized by a severe cardiac phenotype and sensorineural hearing loss $(8,9)$. Due to the limitations in genetic technology, it took nearly four decades before the first LQTS gene was discovered. BrS was reported in 1992 (10), and the first gene, SCN5A, was identified in 1998 (11). The history of genetic discovery in $\mathrm{BrS}$ is shorter than that of LQTS because of the improvement of genetic molecular technology.

In the past decades, Sanger sequencing was used for genetic screening of single-gene diseases and was considered the gold standard for DNA sequencing (12). However, it is laborious and time-consuming. The more recently developed high-throughput next-generation sequencing (NGS) is able to screen hundreds to thousands of genes in a week, a capacity which greatly outstrips that of Sanger sequencing. In addition, NGS can detect singlenucleotide variants in medium- to large-sized regions with high accuracy and reduced cost (13-17). Thus, novel genes can be discovered at a greater speed possible than 
with Sanger sequencing $(13,18-22)$. The main challenge in the rapidly growing field of NGS technologies is to cope with the analysis of a vast sequencing database through advanced bioinformatics tools $(23,24)$. An important advantage of sequencing data is its quality, robustness, and low noise. It should be noted that a successful NGS project requires expertise both in the wet lab and in the realm of bioinformatics in order to produce high quality data and data interpretation.

According to 2011 American/European Heart Rhythm guidelines, genetic testing has become part of standard care in clinical practice (class I recommendation) for SADS and GCM. This is because the inheritable mode of these diseases is mainly autosomal dominant, which means the genetic mutation of parents with SADS has a $50 \%$ chance of being transmitted to parents' children. For example, from a clinical testing standpoint, any patient with a strong clinical index of suspicion for a LQTS diagnosis or an asymptomatic patient with an unequivocal prolonged QTc $(>480 \mathrm{~ms}$ during prepuberty, $>500 \mathrm{~ms}$ during adulthood) in the absence of other clinical conditions should be offered clinical LQTS genetic testing $(25,26)$. As a further illustration, the 2013 HRS/EHRA/APHRS expert consensus recommended that comprehensive or $\mathrm{BrS1}$ (SCN5A)-targeted genetic testing could be useful for patients in whom a cardiologist has established a clinical index of suspicion for BrS based on the patient's clinical history, family history, and the expressed electrocardiographic (resting 12-lead electrocardiography and/or provocative drug challenge testing) phenotype (27). Since disease penetrance of $\mathrm{BrS}$ is incomplete and agerelated, genetic testing may be used for diagnostic purposes and for the screening of at risk family members. In summary, for patients, genetic testing can help doctors make a diagnosis, adjust medications, and predict prognosis. For family members, genetic testing can provide early identification of those family members at risk, and possibly allow early treatment, preventing unnecessary anxiety. Although genetic testing is helpful for SADS patient care, testing genes for which sufficiently strong scientific evidence for disease causation is lacking entails a risk of misinterpreting the genetic information and potentially under/over diagnosing SADS in the patient and family members. Furthermore, ancestral differences may also impact the interpretation of the pathogenicity classification of a variant (28). Consequently, patients may be subjected to unnecessary anxiety and physical consequences. Thus, genes with disputed or limited evidence for causation of these diseases are currently not recommended for diagnostic purposes through routine testing (29-31).

In conclusion, as we enter the era of genomics, the application of high-throughput NGS technology may discover an array of novel genetic variants or genes in inherited diseases, which could revolutionize the understanding of these disease mechanisms. However, the infrastructure of whole genome or whole exome sequencing for clinical practice is not yet mature enough to support a practical understanding in both physicians and patients, who must still struggle with interpreting vast tracts of genetic data.

\section{Acknowledgments}

Funding: None.

\section{Footnote}

Provenance and Peer Review: This article was a free submission to the journal. The article did not undergo external peer review.

Conflicts of Interest: The author has completed the ICMJE uniform disclosure form (available at http://dx.doi. org/10.21037/apm-20-1509). The author has no conflicts of interest to declare.

Ethical Statement: The author is accountable for all aspects of the work in ensuring that questions related to the accuracy or integrity of any part of the work are appropriately investigated and resolved.

Open Access Statement: This is an Open Access article distributed in accordance with the Creative Commons Attribution-NonCommercial-NoDerivs 4.0 International License (CC BY-NC-ND 4.0), which permits the noncommercial replication and distribution of the article with the strict proviso that no changes or edits are made and the original work is properly cited (including links to both the formal publication through the relevant DOI and the license). See: https://creativecommons.org/licenses/by-nc-nd/4.0/.

\section{References}

1. Morita $\mathrm{H}, \mathrm{Wu}$ J, Zipes DP. The QT syndromes: long and short. Lancet 2008;372:750-63.

2. Jervell A, Lange-Nielsen F. Congenital deaf-mutism, functional heart disease with prolongation of the Q-T 
interval and sudden death. Am Heart J 1957;54:59-68.

3. Romano C, Gemme G, Pongiglione R. Rare Cardiac Arrythmias of the Pediatric Age. Ii. Syncopal Attacks Due to Paroxysmal Ventricular Fibrillation. (Presentation of 1st Case in Italian Pediatric Literature). Clin Pediatr (Bologna) 1963;45:656-83.

4. Ward OC. A New Familial Cardiac Syndrome in Children. J Ir Med Assoc 1964;54:103-6.

5. Curran ME, Splawski I, Timothy KW, et al. A molecular basis for cardiac arrhythmia: HERG mutations cause long QT syndrome. Cell 1995;80:795-803.

6. Wang Q, Shen J, Splawski I, et al. SCN5A mutations associated with an inherited cardiac arrhythmia, long QT syndrome. Cell 1995;80:805-11.

7. Skinner JR, Winbo A, Abrams D, et al. Channelopathies That Lead to Sudden Cardiac Death: Clinical and Genetic Aspects. Heart Lung Circ 2019;28:22-30.

8. Tester DJ, Ackerman MJ. Genetic testing for potentially lethal, highly treatable inherited cardiomyopathies/ channelopathies in clinical practice. Circulation 2011;123:1021-37.

9. Schulze-Bahr E, Haverkamp W, Wedekind H, et al. Autosomal recessive long-QT syndrome (Jervell LangeNielsen syndrome) is genetically heterogeneous. Hum Genet 1997;100:573-6.

10. Brugada P, Brugada J. Right bundle branch block, persistent ST segment elevation and sudden cardiac death: a distinct clinical and electrocardiographic syndrome. A multicenter report. J Am Coll Cardiol 1992;20:1391-6.

11. Chen Q, Kirsch GE, Zhang D, et al. Genetic basis and molecular mechanism for idiopathic ventricular fibrillation. Nature 1998;392:293-6.

12. Sanger F, Nicklen S, Coulson AR. DNA sequencing with chain-terminating inhibitors. Proc Natl Acad Sci U S A 1977;74:5463-7.

13. Juang JM, Lu TP, Lai LC, et al. Disease-targeted sequencing of ion channel genes identifies de novo mutations in patients with non-familial Brugada syndrome. Sci Rep 2014;4:6733.

14. Juang JJ, Liu YB, Chen CJ, et al. Validation and Disease Risk Assessment of Previously Reported Genome-Wide Genetic Variants Associated with Brugada Syndrome: SADS-TW BrS Registry. Circ Genom Precis Med 2020;13:e002797.

15. Cordova-Fletes C, Rangel-Sosa MM, Martinez-Jacobo LA, et al. Whole-exome sequencing in three children with sporadic Blau syndrome, one of them co-presenting with recurrent polyserositis. Autoimmunity 2020;53:344-52.
16. Dou J, Wu D, Ding L, et al. Using off-target data from whole-exome sequencing to improve genotyping accuracy, association analysis and polygenic risk prediction. Brief Bioinform 2020. [Epub ahead of print].

17. Hu X, Guo R, Guo J, et al. Parallel Tests of Whole Exome Sequencing and Copy Number Variant Sequencing Increase the Diagnosis Yields of Rare Pediatric Disorders. Front Genet 2020;11:473.

18. Juang JM, Lu TP, Lai LC, et al. Utilizing multiple in silico analyses to identify putative causal SCN5A variants in Brugada syndrome. Sci Rep 2014;4:3850.

19. Walsh T, Shahin H, Elkan-Miller T, et al. Whole exome sequencing and homozygosity mapping identify mutation in the cell polarity protein GPSM2 as the cause of nonsyndromic hearing loss DFNB82. Am J Hum Genet 2010;87:90-4.

20. de Ligt J, Boone PM, Pfundt R, et al. Detection of clinically relevant copy number variants with whole-exome sequencing. Hum Mutat 2013;34:1439-48.

21. Alvarez-Mora MI, Todeschini AL, Caburet S, et al. An exome-wide exploration of cases of primary ovarian insufficiency uncovers novel sequence variants and candidate genes. Clin Genet 2020;98:293-8.

22. Juang JJ, Horie M. Genetics of Brugada syndrome. J Arrhythm 2016;32:418-25.

23. Pareek CS, Smoczynski R, Tretyn A. Sequencing technologies and genome sequencing. J Appl Genet 2011;52:413-35.

24. Day-Williams AG, Zeggini E. The effect of nextgeneration sequencing technology on complex trait research. Eur J Clin Invest 2011;41:561-7.

25. Ackerman MJ, Priori SG, Willems S, et al. HRS/EHRA expert consensus statement on the state of genetic testing for the channelopathies and cardiomyopathies this document was developed as a partnership between the Heart Rhythm Society (HRS) and the European Heart Rhythm Association (EHRA). Heart Rhythm 2011;8:1308-39.

26. Lim GB. Reappraisal of LQTS-causing genes. Nature Reviews Cardiology 2020;17:200-1.

27. Priori SG, Wilde AA, Horie M, et al. Executive summary: HRS/EHRA/APHRS expert consensus statement on the diagnosis and management of patients with inherited primary arrhythmia syndromes. Europace 2013;15:1389-406.

28. Chen CJ, Lu TP, Lin LY, et al. Impact of Ancestral Differences and Reassessment of the Classification of Previously Reported Pathogenic Variants in Patients With 
Brugada Syndrome in the Genomic Era: A SADS-TW BrS Registry. Front Genet 2019;9:680.

29. Hosseini SM, Kim R, Udupa S, et al. Reappraisal of Reported Genes for Sudden Arrhythmic Death: An Evidence-Based Evaluation of Gene Validity for Brugada Syndrome. Circulation 2018;138:1195-205.

30. Ingles J, Semsarian C. Time to Rethink the Genetic Architecture of Long QT Syndrome. Circulation

Cite this article as: Lai LP. Clinical implication of nextgeneration sequencing for sudden arrhythmia death syndrome. Ann Palliat Med 2020;9(6):4408-4411. doi: 10.21037/apm-20-1509
2020;141:440-3.

31. Adler A, Novelli V, Amin AS, et al. An International, Multicentered, Evidence-Based Reappraisal of Genes Reported to Cause Congenital Long QT Syndrome. Circulation 2020;141:418-28.

(English Language Editor: J. Gray) 